\title{
BMJ Prevalence and persistence of Open depression among undergraduate medical students: a longitudinal study at one UK medical school
}

\author{
Thelma A Quince, ${ }^{1}$ Diana F Wood, ${ }^{2}$ Richard A Parker, ${ }^{1}$ John Benson ${ }^{1}$
}

To cite: Quince TA, Wood DF, Parker RA, et al. Prevalence and persistence of depression among undergraduate medical students: a longitudinal study at one UK medical school. BMJ Open 2012;00:e001519. doi:10.1136/bmjopen-2012001519

- Prepublication history and additional material for this paper are available online. To view these files please visit the journal online (http://dx.doi.org/10.1136/ bmjopen-2012-0011519).

Received 22 May 2012 Accepted 2 July 2012

This final article is available for use under the terms of the Creative Commons Attribution Non-Commercial 2.0 Licence; see http://bmjopen.bmj.com

${ }^{1}$ Primary Care Unit, Department of Public Health and Primary Care, University of Cambridge, Institute of Public Health, Cambridge, UK ${ }^{2}$ School of Clinical Medicine, University of Cambridge, Cambridge, UK

\section{Correspondence to} Dr Thelma A Quince; taq1000@medschl.cam.ac.uk

\section{ABSTRACT}

Objectives: To determine the prevalence of depression among male and female medical students, its change over time and whether depression persists for affected students.

Design: Longitudinal study comprising annual questionnaire surveys which included the depression subscale of the Hospital Anxiety and Depression Scale (HADS-D).

Participants: Between 2007 and 2010 all 1112 students entering the Core Science component (Year 1) and all 542 students entering the Clinical component (Year 4) of the Cambridge (UK) medical course were followed-up annually.

Methods: We analysed, separately for men and women, mean HADS-D scores, the proportions whose scores indicated depression at different time-points and for students maintaining participation, the number of occasions on which their HADS-D scores indicated depression.

Results: 725 Core Science and 364 Clinical students participated. Mean HADS-D scores ranged between 3.34 and 3.49 among all Core Science students and between 2.16 and 2.91 among all Clinical students. There was no difference between men and women in median HADS-D scores. Prevalence of depression ranged between $5.7 \%$ and $10.6 \%$ among all Core Science students and between $2.7 \%$ and $8.2 \%$ among all Clinical students.

Over time Core Science students displayed no increase in mean HADS-D score. Among Clinical students only men displayed a small increase (time coefficient 0.33 $(95 \% \mathrm{Cl} 0.11$ to 0.55$))$. Prevalence did not increase over time. 220 Core Science and 150 Clinical students participated throughout the study. Of these, $18.2 \%$ and $10.6 \%$, respectively, recorded HADS-D scores indicating depression on at least one occasion. Of 56 students recording depression at some point, 37 did so only once. Conclusions: Prevalence of depression among participants was similar to that reported for comparable groups. Among men approaching the end of clinical studies depression scores increased. In all years a minority of students displayed depression; for some this persisted. Mechanisms are needed to identify and support students suffering from depression, particularly when persistent.

\section{ARTICLE SUMMARY}

Article focus

- What is the prevalence of depression among male and female medical students?

- Does prevalence of depression increase or decrease during the course?

- For those affected, is depression persistent?

Key messages

- Although prevalence of depression among medical students was not higher than that found comparable groups a significant minority of students displayed depression, the majority of these did so only on one occasion.

- Prevalence was not found to increase over time.

- Although the majority of students who demonstrated depression did so only on one occasion, mechanisms are needed to identify and support depressed students.

Strengths and limitations of this study

- Data obtained from students in all 6 years of medical undergraduate training.

- Use of a validated survey instrument allowing comparison with comparable groups.

- Results of missing value analysis together with response rates indicate the generalisability of study results to the institution in which the study was conducted.

- Study undertaken in one UK medical school undertaking a traditional medical course limits generalisability.

- Course structure results in only half of students in the Core Science component being able to transfer to Clinical component so limiting longitudinal nature of study.

- Attrition of response rate.

- Use of a single simple self-report instrument.

\section{INTRODUCTION}

Psychological well-being is important for medical students, for the patients they meet and for their future medical practice. ${ }^{1-4}$ Medical students with depression more commonly consider dropping out of their course. ${ }^{5}$ 
Among newly qualified physicians, associations have been found between depressive symptoms and increasing cynicism, self-perceived medical errors and lower levels of selfrated health. ${ }^{6-8}$ As their careers progress, physicians have elevated rates of suicide compared to the general population. ${ }^{9-12}$ Patient care is affected by psychological distress among physicians: poor communication, diminished quality of care and medical errors have been found to be associated with physician stress. ${ }^{13} 14$

Physicians are more likely to experience depression compared to the general population. ${ }^{9-12}$ However, the prevalence of depression among medical students varies, depending on age, stage of training, methods of measurement and location. ${ }^{15}$ The use of different study instruments limits the extent to which medical students can be compared directly with similarly aged populations. Even where valid comparisons have been made, evidence remains conflicting. ${ }^{16-20}$

Gender differences in depression have been found in both practicing and newly qualified physicians, which mirror epidemiological studies indicating that depression is more common among women than men. ${ }^{21} \mathrm{~A}$ study of US residents found that $45 \%$ of women compared with $32 \%$ of men reported 4 or 5 depressive symptoms. ${ }^{6}$ Most, but not all, studies conducted among medical students, using various instruments, show a similar pattern..$^{15} 202223$

The prevailing view is that depression rises during undergraduate medical education and that this rise is more pronounced among women. ${ }^{15} 20{ }^{24}$ However, this pattern is not universally reported: studies among some medical student populations show levels of depression fall between years 1 and 2 and between preclinical and clinical stages of training. ${ }^{22}{ }^{23}$ Longitudinal studies in the UK and Sweden suggest that some students repeatedly experience psychological distress during medical training, ${ }^{25} 26$ but few studies have examined whether depression for an individual student is persistent.

The School of Clinical Medicine at the University of Cambridge is engaged in a study of factors in undergraduate education that may influence the quality of patient care provided by students in their subsequent medical practice. We regard student depression as one such factor. In October 2007, we began a longitudinal study involving all students coming to Cambridge to study medicine. This paper reports the findings with respect to three questions concerning male and female medical students.

1. What is the prevalence of depression?

2. Does prevalence of depression increase or decrease during the course?

3. For those affected, is depression persistent?

\section{METHODS}

\section{Participants}

The medical course at Cambridge comprises a Core Science component (Years 1-3) during which students learn core medical science with a small element of clinical experience leading to a primary BA degree, and a Clinical component (Years 4-6). Around 280 students, typically aged $18-19$ years, enter Year 1 . At the end of Year 3, approximately half continue into the Clinical component in Cambridge. All 1112 students entering the Core Science component (Year 1) and all 542 students entering the Clinical component (Year 4) between 2007 and 2010 were followed up annually. Students were invited to participate in a longitudinal study comprising annual questionnaire surveys. Students entering the Clinical component in 2010 comprised those students who had entered the Core Science component in 2007 and who remained in Cambridge.

\section{Outcome measure}

We measured depression using the depression subscale of the Hospital Anxiety and Depression Scale (HADS-D). ${ }^{27}$ HADS is a self-report instrument initially developed to evaluate the presence and severity of anxiety and depression in general medical populations. It is regarded as a useful tool for identifying those with emotional distress and has good psychometric properties. $^{28}{ }^{29}$ HADS-D has been widely used in the UK among members of the general population, ${ }^{30}$ among young adults within the general population, ${ }^{31}$ with undergraduates, ${ }^{32} \quad 33$ medical students ${ }^{16} \quad 34 \quad 35$ and medical practitioners. ${ }^{36} 37$

HADS-D comprises seven items expressed both positively and negatively, giving a maximum score of 21 . It has widely recognised norms relating to depression: scores of $0-7$ are regarded as 'normal', scores of 8-10 indicate 'possible' depression and scores of 11 and over indicate 'probable' depression. The HADS-D norm of $\geq 8$ has been shown to have a sensitivity of $0.82(95 \%$ CI 0.73 to 0.89 ) and a specificity of 0.74 (95\% CI 0.60 to 0.84). ${ }^{29}$ A study of UK undergraduates comparing results for HADS-D with interview data concluded that the HADS-D scale was a reasonably accurate indicator of depressive conditions in university students at the recommended cut-offs. ${ }^{38}$

\section{Procedures}

Students in years 1-5 received questionnaires during the first week of each new academic year (September/ October). Students in Year 6 received questionnaires in January of their final year, prior to final examinations in June. We used a paper-based questionnaire for all students in 2007 and 2008 and for Clinical students in 2009. We used an online questionnaire for Core Science students in 2009 and for all students in 2010 (table 1). Participation was voluntary. Questionnaires were labelled by study number only. A study data manager (who had no access to results) sent one reminder to students after 2 weeks. A small prize was awarded annually by lottery to a small number of participants. The study received approval from the University of Cambridge Psychology Ethics Committee. 
Table 1 Number of participating students providing depression scores at each year for each component of the course

\begin{tabular}{|c|c|c|c|c|}
\hline & \multicolumn{4}{|c|}{ Participating students in each year of course ( $\%$ of year group) ( $\%$ of female) } \\
\hline & \multicolumn{4}{|l|}{ Core Science component } \\
\hline & \multirow[b]{2}{*}{ Total number of entrants } & \multicolumn{3}{|c|}{ Year of component } \\
\hline & & Year 1 & Year 2 & Year 3 \\
\hline Students entering 2007 & $266(52.2)$ & $182(68.4)(51.1)$ & $142(53.4)(52.8)$ & $121(45.5)(53.7)$ \\
\hline Students entering 2008 & $283(45.8)$ & 139 (49.1) (58.3) & 87 (30.7) (60.9) & 78 (27.6) (60.2) \\
\hline Students entering 2009 & $281(48.9)$ & $156(55.5)(53.2)$ & 94 (33.4) (53.2) & $84(29.9)(57.1)$ \\
\hline Students entering 2010 & $282(46.3)$ & $188(67.0)(50.5)$ & 107 (37.9) (50.5) & \\
\hline \multirow[t]{4}{*}{ Total } & $1112(48.0)$ & 665 (59.8) (52.9) & 430 (38.7) (53.9) & $283(25.4)(56.5)$ \\
\hline & \multicolumn{4}{|l|}{ Clinical component } \\
\hline & & \multicolumn{3}{|c|}{ Year of component } \\
\hline & Total number of entrants & Year 4 & Year 5 & Year 6 \\
\hline Students entering 2007 & $135(61.1)$ & $102(75.6)(62.7)$ & $82(60.7)(67.1)$ & 76 (56.3) (67.1) \\
\hline Students entering 2008 & $135(44.3)$ & 97 (71.9) (54.6) & 70 (51.9) (58.6) & 57 (42.2) (63.2) \\
\hline Students entering 2009 & $135(49.6)$ & $70(51.9)(46.4)$ & $47(34.8)(45.7)$ & 49 (36.3) (45.8) \\
\hline Students entering 2010 & 137 (53.3) & 68 (49.6) (50.0) & $63(46.0)(55.6$ & \\
\hline Total & $542(52.0)$ & 337 (62.2) (54.3 & $262(48.3(58.0)$ & 182 (33.6) (59.9) \\
\hline
\end{tabular}

\section{Analysis}

\section{Overall approach}

We took an HADS-D of $\geq 8$ to indicate depression. We set statistical significance at the $5 \%$ level $(p<0.05)$ for all analyses. Only about half of the Core Science students present in Years 1-3 remained in Cambridge for Years 4-6, yielding small numbers for analysis across all 6 years (table 1). For this reason, we analysed data separately for students from the Core Science and Clinical components.

For study questions 1 and 2 (prevalence of depression) we included all students completing questionnaires between 2007 and 2011. For study question 3 (persistence of depression) we included students entering either the Core Science or the Clinical component in 2007, 2008 and 2009, who maintained their participation for all years of their respective course.

\section{Response bias}

For study questions 1 and 2 (prevalence of depression), we undertook missing value analyses for men and women separately, using logistic regression to determine whether HADS-D on entry predicted subsequent study participation. Outcome variables were missing values (yes or no) for HADS-D at Years 2 and 3 for students entering year 1 and Years 5 and 6 for students entering year 4 . The explanatory variable was HADS-D at Year 1 for Core Science students and Year 4 for Clinical students. We included 'year of course entry' as an explanatory factor to adjust for student cohort. Students entering in 2010 were considered to have missing subsequent participation if they did not respond in Year 2/Year 5. We calculated ORs corresponding to the increased risk of non-response for every 1 unit increase in HADS-D at course entry, with $95 \%$ CIs for ORs and $p$ values.

For study question 3 (persistence of depression) within each component we undertook separate t tests to examine whether there was any difference in the mean scores of those who maintained their participation and those who did not.

\section{Detailed analyses}

For study question 1 (prevalence of depression) we measured separately for men and women, at each point in the course, mean HADS-D and the proportion with HADS-D scores $\geq 8$ indicating depression. We compared median HADS-D among men and women using nonparametric tests (Mann-Whitney U tests) and the proportions of men and women whose HADS-D indicated depression ( $\chi^{2}$ tests).

For study question 2 (prevalence of depression over time) we undertook regression analyses separately for men and women, using a 'Generalised Estimating Equations' (GEE) method. We chose the GEE method because many students had repeated data, the HADS-D scores were skewed and we did not want to make any full distributional assumptions. The model assumed a general (unstructured) correlation structure. In order to adjust for the effect of student year of entry, we included this as an explanatory factor variable. To test the robustness of our model we applied a sensitivity analysis to the outcome variables, removing outliers more than $3 \mathrm{SD}$ away from the mean.

For study question 3 (persistence of depression) we examined separately for men and women the number of occasions in which individual students' HADS-D score indicated depression. Within each component we examined whether the proportions of men and women whose score indicated depression differed (1) on any occasion, (2) on only one occasion or (3) on more than one occasion. Given the small sample size we used Newcombe's method $^{39}$ with $\mathrm{R}$ software ${ }^{40}$ to calculate differences in independent (ie, unpaired) proportions together with 95\% CIs. 
Table 2 Missing value analysis: logistic regression results presented as ORs, 95\% Cls and $p$ values for relationship between HADS-D on entry and subsequent study participation, adjusting for student cohort

\begin{tabular}{|c|c|c|}
\hline $\begin{array}{l}\text { Depression } \\
\text { (HADS-D) }\end{array}$ & Men & Women \\
\hline \multicolumn{3}{|c|}{ Core Science component students } \\
\hline OR $(95 \% \mathrm{Cl})$ & $1.05(0.95$ to 1.16$)$ & 1.08 (0.99 to 1.18$)$ \\
\hline $\mathrm{p}$ Values & 0.35 & 0.08 \\
\hline \multicolumn{3}{|c|}{ Clinical component students } \\
\hline OR $(95 \% \mathrm{Cl})$ & $1.07(0.91$ to 1.25$)$ & $0.95(0.79$ to 1.15$)$ \\
\hline p Values & 0.43 & 0.62 \\
\hline
\end{tabular}

HADS-D, depression subscale of the Hospital Anxiety and Depression Scale

\section{RESULTS}

Participants

In total 725 Core Science and 364 Clinical students participated in the study. Table 1 shows the number of entrants to the Core Science and Clinical components for each year of entry (2007-2010) and those participating each year and providing depression data.

\section{Response bias}

Table 2 shows the results of the missing value analysis for study questions 1 and 2. For students in both components of the course, there was no significant relationship between HADS-D on entry and subsequent study participation. For study question 3, no statistically significant difference in mean HADS-D was found between students who maintained their participation and those who did not (analyses not shown).

\section{Prevalence of depression among men and women} (study question 1)

Table 3 shows, at each point in the course, mean HADS-D and the proportion of students whose HADS-D indicated depression.

\section{Core Science component}

Mean HADS-D ranged between 3.34 and 3.49. The proportion of students whose HADS-D scores indicated depression ranged between $5.7 \% \quad(5.8 \%$ among men and $5.7 \%$ among women) and $10.6 \%$ (14.8\% among men and $7.5 \%$ among women).

\section{Clinical component}

Mean HADS-D ranged between 2.16 and 2.91. The proportion of students whose HADS-D scores indicated depression ranged between 2.7\% (3.2\% among men and $2.2 \%$ among women) and $8.2 \%$ (5.6\% among men and $10 \%$ among women).

Table 3 shows comparisons, at each point in the medical course, between median HADS-D among men and women (Mann-Whitney $U$ tests). There were no significant gender differences in either course component.

Table 3 also shows the proportions of men and women whose HADS-D indicated depression $\left(\chi^{2}\right.$ tests $)$. Among Core Science component students, significantly more men than women in year 3 recorded HADS-D scores indicating depression, but there were no differences in other years. There were no significant differences between men and women in the Clinical component.

Table 3 Mean HADS-D (SD) and percentages of participants whose HADS-D indicated depression by gender for each year of course within each component. Non-parametric gender comparison of means and $\chi^{2}$ gender comparisons of percentages

\begin{tabular}{|c|c|c|c|c|}
\hline & \multicolumn{3}{|c|}{ Mean scores (SD) } & \multirow{2}{*}{$\begin{array}{l}\text { Mann-Whitney } U \text { tes } \\
\text { ( } p \text { value) }\end{array}$} \\
\hline & All & Men & Women & \\
\hline \multicolumn{5}{|c|}{ Core Science component students } \\
\hline Year $1(n=665 / 313 / 352)$ & $3.34(2.36)$ & $3.22(2.24)$ & $3.44(2.47)$ & 0.339 \\
\hline Year $2(n=429 / 197 / 232)$ & $3.49(2.75)$ & $3.29(2.77)$ & $3.66(2.76)$ & 0.120 \\
\hline Year $3(n=282 / 122 / 160)$ & $3.35(2.85)$ & $3.77(3.16)$ & $3.04(2.56)$ & 0.062 \\
\hline \multicolumn{5}{|c|}{ Clinical component students } \\
\hline Year $4(n=337 / 157 / 180)$ & $2.16(2.08)$ & $2.23(2.06)$ & $2.10(2.11)$ & 0.474 \\
\hline Year $5(n=260 / 109 / 151)$ & $2.65(2.51)$ & $2.82(2.66)$ & $2.52(2.40)$ & 0.398 \\
\hline \multirow[t]{2}{*}{ Year $6(n=182 / 72 / 110)$} & $2.91(2.92)$ & $3.08(2.88)$ & $2.79(2.96)$ & 0.311 \\
\hline & \multicolumn{3}{|c|}{$\begin{array}{l}\text { Prevalence } \\
\text { Depression (\%) ( } \geq 8)\end{array}$} & $\chi^{2}$ \\
\hline \multicolumn{5}{|c|}{ Core Science component students } \\
\hline Year $1(n=665 / 313 / 352)$ & 5.7 & $5.8 \%$ & $5.7 \%$ & $0.969^{*}$ \\
\hline Year 2 (n=429/197/232) & 8.4 & $7.1 \%$ & $9.5 \%$ & $0.376^{\star}$ \\
\hline Year $3(n=282 / 122 / 160)$ & 10.6 & $14.8 \%$ & $7.5 \%$ & $0.050^{*}$ \\
\hline \multicolumn{5}{|l|}{ Clinical component students } \\
\hline Year $4(n=337 / 157 / 180)$ & 2.7 & $3.2 \%$ & $2.2 \%$ & $0.585^{\star}$ \\
\hline Year $5(n=260 / 109 / 151$ & 5.8 & $6.4 \%$ & $5.3 \%$ & $0.701^{*}$ \\
\hline Year $6(n=182 / 72 / 110)$ & 8.2 & $5.6 \%$ & $10.0 \%$ & $0.286^{*}$ \\
\hline
\end{tabular}


Table 4 Linear time coefficients resulting from Generalised Estimating Equations regression analyses on the outcome variable HADS-D, adjusting for student year of entry, presented with $95 \% \mathrm{Cls}$

\begin{tabular}{|c|c|c|}
\hline & Men & Women \\
\hline \multicolumn{3}{|c|}{$\begin{array}{l}\text { Core Science component students } \\
\text { Depression (HADS-D) }\end{array}$} \\
\hline $\begin{array}{l}\text { Time coefficients } \\
(95 \% \mathrm{Cl})\end{array}$ & $\begin{array}{l}0.20 \\
(-0.03 \text { to } 0.43)\end{array}$ & $\begin{array}{l}-0.11 \\
(-0.31 \text { to } 0.08)\end{array}$ \\
\hline \multicolumn{3}{|c|}{ Clinical component students } \\
\hline $\begin{array}{l}\text { Time coefficients } \\
(95 \% \mathrm{Cl})\end{array}$ & $\begin{array}{l}0.33 \\
(0.11 \text { to } 0.55) \\
\end{array}$ & $\begin{array}{l}0.17 \\
(-0.04 \text { to } 0.39)\end{array}$ \\
\hline
\end{tabular}

All results were similar after removal of outliers more than three SD from the mean.

HADS-D, depression subscale of the Hospital Anxiety and

Depression Scale.

\section{Prevalence of depression among men and women over time (study question 2)}

Table 4 shows the results of the GEE models used in this analysis. These are supported by the finding reported above that missing values were not significantly dependent on initial depression levels (table 2). The time coefficient resulting from a GEE model should be interpreted as representing a population-averaged effect rather than an individual student-level effect.

\section{Core Science component}

The results indicate no significant difference, among either men or women, in HADS-D scores over time. Sensitivity analysis (removal of outliers) produced similar results.

\section{Clinical component}

A very small but statistically significant increase in HADS-D over time was found among men. No significant difference over time was found among women. Sensitivity analysis (removal of outliers) produced similar results.

\section{Persistence of depression among men and women (study question 3)}

Table 5 shows the prevalence of depression recorded by students who maintained their participation throughout the 3 years of each course component.

\section{Core Science component}

Among the 96 men and 124 women who maintained their participation, 40 students ( 17 men and 23 women) recorded at least one HADS-D score indicating depression. Of these, 29 (9 men and 20 women) did so on only one occasion; 9 (6 men and 3 women) did so on two occasions. Two men recorded scores indicating "possible' depression throughout the Core Science course component.

\section{Clinical component}

Among the 59 men and 91 women who maintained their participation, 16 students (5 men and 11 women) recorded at least one HADS-D score indicating depression. Of these, 8 ( 3 men and 5 women) did so on one occasion; 6 (all women) did so on two occasions. Two men recorded scores indicating 'possible' depression throughout the Clinical course component.

Table 5 also shows the results of comparisons between men and women with respect to transitory or persistent depression. There were no-significant gender differences in either course component.

\section{DISCUSSION}

Among groups of male and female medical students in Cambridge, the prevalence of depression varied from $2.2 \%$ to $14.8 \%$. No significant changes in mean depression scores were observed among Core Science component students or among women in the Clinical component. A statistically significant increase in mean depression scores was found for men during the Clinical component. However, this increase was extremely small when considered against the 21 points of the HADS-D scale. Most students who demonstrated depression

Table 5 Prevalence of depression recorded by repeat participants

\begin{tabular}{|c|c|c|c|c|}
\hline & All & Men & Women & $\begin{array}{l}\text { Differences in proportion } \\
\text { women-men }(95 \% \mathrm{CI})\end{array}$ \\
\hline Core Science component students & $\begin{array}{l}\mathrm{n}=220 \text { (\% of } \\
\text { participants) }\end{array}$ & $\begin{array}{l}\mathrm{n}=96 \text { (\% of } \\
\text { participants) }\end{array}$ & $\begin{array}{l}\mathrm{n}=124 \text { (\% of } \\
\text { participants) }\end{array}$ & \\
\hline On any occasion & $40(18.2)$ & $17(17.7)$ & $23(18.5)$ & $0.008(-0.10$ to 0.11$)$ \\
\hline On only one occasion & $29(13.2)$ & $9(9.4)$ & $20(16.1)$ & $0.07(-0.03$ to 0.15$)$ \\
\hline On more than one occasion & $11(5.0)$ & $8(8.3)$ & $3(2.4)$ & $-0.06(-0.13$ to 0.001$)$ \\
\hline On any occasion & $16(10.6)$ & $5(8.5)$ & $11(12.1)$ & $0.04(-0.08$ to 0.13$)$ \\
\hline On only one occasion & $8(5.3)$ & $3(5.1)$ & $5(5.5)$ & $0.004(-0.09$ to 0.08$)$ \\
\hline On more than one occasion & $8(5.3)$ & $2(3.4)$ & $6(6.6)$ & $0.03(-0.06$ to 0.11$)$ \\
\hline
\end{tabular}


during the Core Science component did so only on one occasion. In the Clinical component, although few students experienced depression, half did so on more than one occasion. We found no evidence that women were more likely than men to experience depression, either on one occasion or persistently.

Our study obtained data on depression from students in all 6 years of medical training. In the Core Science component, for each year of the course between $25.4 \%$ and $59.8 \%$ of those eligible participated. Comparable figures for the Clinical component were 33.6-62.2\%. Almost 27\% of Core Science students and 37\% of Clinical students entering between 2007 and 2009 participated on all occasions during their respective course components, allowing longitudinal observations to be made. These participation rates, allied with missing data analyses indicating that initial scores did not predict later non-response, support the generalisability of our results to the population of medical students at the University of Cambridge. Where possible, these results are related to the existing literature using HADS-D in order to allow direct comparison.

Mean HADS-D scores recorded by students in our study ranged from 2.16 (SD 2.08) for Clinical students in year 4 of the course to 3.49 (SD 2.75) for Core Science students in year 2 . These are roughly similar to mean scores reported for comparable groups: scores from 2.68 to 7.5 for medical students elsewhere, ${ }^{17} 1934$ and from 2.33 to 5.2 for non-medical undergraduate populations. ${ }^{41-43}$

Mean scores may not reflect the prevalence of significant depression. Using the HADS-D score of $\geq 8$, we found that the prevalence of depression ranged from $2.7 \%$ for Clinical students in year 4 of the course to $10.6 \%$ for Core Science students in year 3. Prevalence of depression using a similar cut-off score among comparable groups has been found to vary from $9.5 \%$ to $29 \%$ for medical students, ${ }^{161719}$ and from $3.8 \%$ to $18 \%$ for nonmedical undergraduates. ${ }^{38} 41$ Studies in the general population in Norway and the UK have reported a prevalence of $8 \%$ and $12 \%$, respectively, ${ }^{30} 44$ while a study of people aged 18-25 reported a prevalence of $12 \%$ among men and $18 \%$ among women. ${ }^{31}$ Our results suggest that Cambridge medical students do not have a higher prevalence of depression than students in general or comparable non-student members of the general population. Other work, investigating the suicide rate among students at the University of Cambridge over the period 1970-1996 also found that rates were similar to comparable age groups in the general population. ${ }^{45}$

Although studies involving similarly aged members of the general population have reported a higher prevalence of depression among women compared to men, ${ }^{3144}$ we found no significant gender differences in either mean HADS-D or prevalence of depression in any year of the course. This replicates previous findings using the HADS with other undergraduates including medical and dental students. ${ }^{46} 47$
Turning to the question of whether psychological wellbeing deteriorates during university medical education a UK study of non-medical undergraduates found a significant increase in the proportion recording depression between the period immediately prior to the start of the course and the middle of the second academic year. ${ }^{33}$ Few studies have examined the persistence of depression within individual students over time. In our study, regression analyses indicated no significant change for either men or women throughout the equivalent Core Science component of the course. Analysis of students in the Clinical component indicated a very small increase in mean scores for depression for men but not for women. These minor increases in mean depression scores may be related to the approach of finals examinations, or they may presage the known increase in depression seen among practising doctors.

For many students, the experience of depression was transient. Among repeat participants, 40 Core Science and 16 Clinical students recorded HADS-D scores indicating depression at some point. Of these 56 students, 37 did so on only one occasion. Nevertheless, 19 students (11 Core Science and 8 Clinical) showed evidence of repeated depression, with four men (2 in each component of the course) doing so in all 3 years of their respective course component. We found no significant difference in transient or persistent raised levels of depression between men and women.

The authors are not aware of any other studies using HADS-D of medical students against which to set these particular findings. However, their key implication is that while the overall persistence of depression is low, there exists a small, important minority of students for whom depression is an ongoing experience. It is vital for medical schools to recognise and support all students experiencing depression, but in particular to consider how best to encourage this especially vulnerable group to seek help, given the evidence that suggests their reluctance to do so. ${ }^{1} 264849$

The HADS-D is a well-validated and widely used selfreport instrument. The procedures for administering the survey were created to ensure anonymity and confidentiality. ${ }^{50}$ This study is limited by being based on one UK university, providing a 'traditional' course with a collegiate pastoral support structure. There may have been a systematic difference between those participating and those not participating (ie, a non response bias) which may have affected our results. However, the missing value analysis supports the view that those continuing to participate could be considered representative of all student entrants in their year group and that continued participation was not influenced by scores for HADS-D recorded at the beginning of participation. We cannot exclude the possibility of an association between an unobserved change in depression and the missing values.

We tested for a linear relationship between year of course and depression which rests on the assumption that depression increases or decreases gradually over 
time. In reality this may not have been the case: mean scores could rise during 1 year and then decline during the next year. Unfortunately, our sample size was too small and number of time points too few to test for quadratic or other polynomial relationships between individual course years and depression, but future studies may like to consider this.

Future work should investigate the generalisability of these results to other medical schools in the UK and, in order to extend the relevance of findings to future patient care, the relationship between depression during undergraduate medical education and 'burnout' after qualification. Further work is needed on identifying both transient and repeated experiences of depression among medical students and understanding possible causes related to course design and students' experience of it. For example, studies of students have found depressive symptoms to be related to prior mental health problems, ${ }^{49}$ personality aspects such as maladaptive perfectionism ${ }^{51}$ and strong feelings of altruism and empathy. ${ }^{52}$

\section{CONCLUSIONS}

Overall, only a small proportion of the student body experienced depression. These findings do not support the view that medical students exhibit a higher prevalence of depression than other comparable groups or that differences in mean depression score or prevalence exist between men and women. Nevertheless, depression may start to become more prevalent as medical qualification approaches and a small number of students who experience depression do not recover from one year to the next. It is important that mechanisms should be in place to identify and support all students suffering from depression, but particularly the very few with persistent low mood. As part of this process, it remains important to challenge the stigma of mood disorder among health professionals to encourage students experiencing difficulty to seek and receive appropriate help.

Acknowledgements The authors are indebted to James Brimicombe, Data Manager of the Primary Care Unit, Department of Public Health and Primary Care, University of Cambridge, for his administration of the online survey.

Contributors TQ, JB and DW were responsible for the conception and design of the study. TQ coordinated the study and managed the data collection. TQ and RP did the analyses, JB and DW contributed to interpretation of the findings. TQ wrote the first draft of the manuscript. All authors had full access to all data and all were involved in critical revision of the manuscript.

Competing interests All authors have completed the Unified Competing Interest form at www.icmje.org/coi_disclosure.pdf (available on request from the corresponding author) and declare: no support from any organisation for the submitted work; no financial relationships with any organisations that might have an interest in the submitted work in the previous 3 years; no other relationships or activities that could appear to have influenced the submitted work.

Ethics approval The study was approved by the University of Cambridge Psychology Ethics Committee.

Provenance and peer review Not commissioned; externally peer reviewed.

Data sharing statement No additional data are available.

\section{REFERENCES}

1. Tyssen R, Vaglum P, Grønvold NT, et al. Factors in medical school that predict postgraduate mental health problems in need of treatment. A nationwide and longitudinal study. Med Educ 2001;35:110-20.

2. Royal College of Psychiatrists. The mental health of students in higher education. Council Report CR112 January 2003, London: Royal College of Psychiatrists, 2003.

3. Tyssen R, Hem E, Vaglum P, et al. The process of suicidal planning among medical doctors: predictors in a longitudinal Norwegian sample. J Affect Disord 2004;80:191-8.

4. Dunn LB, Iglewicz A, Moutier C. A conceptual model of students well-being: promoting resilience and preventing burnout. Acad Psychiatry 2008;32:44-53.

5. Dyrbye LN, Thomas MR, Power DV, et al. Burnout and serious thoughts of dropping out of medical school: a multi-institutional study. Acad Med 2010a;85:94-102.

6. Collier VU, McCue JD, Markus A, et al. Stress in medical residency: status Quo after a decade or reform? Ann Intern Med 2002;136:384-90.

7. West CP, Tan AD, Habermann TM, et al. Association of resident fatigue and distress with perceived medical errors. JAMA 2009;302:1294-300.

8. Yi MS, Mrus JM, Mueller CV, et al. Self rated health of primary care house officers and its relationship to psychological and spiritual well-being. BMC Med Educ 2007;7:9.

9. Lindeman $\mathrm{S}$, Laara $\mathrm{E}$, Hakko $\mathrm{H}$, et al. A systematic review on gender-specific suicide mortality in medical doctors. Br J Psychiatry 1996;168:274-93.

10. Schernhammer ES, Colditz GA. Suicide rates among physicians: a quantitative and gender assessment (meta-analysis). Am J Psychiatry 2004;161:2295-303.

11. Meltzer H, Griffiths C, Brock A, et al. Patterns of suicide by occupation in England and Wales. Br J Psychiatry 2008;193:73-6.

12. Tyssen $R$, Hem $E$, Gude $T$, et al. Lower life satisfaction in physicians compared with a general population sample: a 10-year longitudingal nationwide study of course and predictors. Soc Psychiatry Psychiatr Epidemiol 2009;44:47-54.

13. Firth-Cozens J, Greenhalgh J. Doctors' perceptions of the links between stress and lowered clinical care. Soc Sci Med 1997:44:1017-22.

14. Brown R, Dunn S, Byrnes K, et al. Doctors' stress responses and poor communication performance in simulated bad-news consultations. Acad Med 2009;84:1595.

15. Dyrbye LN, Thomas MR, Shanafelt TD. Systematic review of depression, anxiety and other indicators of psychological distress among US and Canadian medical students. Acad Med 2006;81:354-73.

16. Pickard $\mathrm{M}$, Bates $\mathrm{L}$, Dorian $\mathrm{M}$, et al. Alcohol and drug use in second year medical students at the University of Leeds. Med Educ 2000;34:148-50.

17. Karaoglu N, Seker M. Anxiety and depression in medical students related to desire for and expectations from a medical career. West Indian Med J 2010:59:196-202.

18. Curran TA, Gawley E, Casey P, et al. Depression, suicidality and alcohol abuse among medical and business students. Ir Med J 2009;102:249-52.

19. Bunevicius A, Katkute A, Bunevicius R. Symptoms of anxiety and depression in medical students and in humanities students: relationship with Big-Five personality dimensions and vulnerability to stress. Int J Soc Psychiatry 2008;54:494-501.

20. Dahlin ME, Joneborg N, Runeson B. Stress and depression among medical students: a cross-sectional study. Med Educ 2005;39:594-604.

21. Kessler RC. Epidemiology of women and depression. J Affect Disord 2003;74:5-13.

22. Sreeramareddy CT, Shankar PR, Binu VS, et al. Psychological morbidity, sources of stress and coping strategies among undergraduate medical students of Nepal. BMC Med Educ 2007;7:26.

23. Mancevska S, Bozinovska L, Tecce J, et al. Depression, anxiety and substance use in medical students in the Republic of Macedonia Bratisl Lek Listy 2008;109:568-72.

24. Rosal MC, Ockene IS, Ockene JK, et al. A longitudinal study of students' depression at one medical school. Acad Med 1997;72:542-6.

25. Guthrie E, Black D, Bagalkote $\mathrm{H}$, et al. Psychological stress and burnout in medical students: a five-year prospective longitudinal study. J Royal Soc Med 1998;91:237-43.

26. Dahlin ME, Runeson B. Burnout and psychiatric morbidity among medical students entering clinical training: a three year 
prospective questionnaire and interview based study. BMC Med Educ 2007;7:6.

27. Zigmond AS, Snaith RP. The hospital anxiety and depression scale. Acta Psychiatr Scand 1983;67:361-70.

28. Brennan C, Worrall-Davies A, McMillan D, et al. The hospital anxiety and depression scale: a diagnostic meta-analysis of case-finding ability. J Psychosom Res 2010;69:371-8.

29. Bjelland I, Dahl AA, Tangen Haug T, et al. The validity of the hospital anxiety and depression scale: an updated literature review. J Psychosom Res 2002;52:69-77.

30. Green MJ, Benzeval M. Ageing, social class and common mental disorders: longitudinal evidence from three cohorts in the West of Scotland. Psychol Med 2011;41:565-74.

31. Mallen C, Mottram S, Thomas E. Birth factors and common mental health problems in young adults. Soc Psychiatr Epidemiol 2008;43:325-30.

32. Webb $\mathrm{E}$, Ashton $\mathrm{CH}$, Kelly $\mathrm{P}$, et al. Alcohol and drug use in UK university students. Lancet 1996;348:922-5.

33. Andrews $B$, Wilding JM. The relation of depression and anxiety to life-stress and achievement in students. Br J Psychol 2004;95:509-21.

34. Woolf K, Cave J, McManus C, et al. 'It gives you an understanding you can't get from any book.' The relationship between medical students' and doctors' personal illness experiences and their performance: a qualitative and quantitative study. BMC Med Educ 2007;7:50.

35. Ashton $\mathrm{CH}$, Kamali F. Personality, lifestyles, alcohol and drug consumption in a sample of British medical students. Med Educ 1995;29:187-92.

36. Caplan RP. Stress, anxiety and depression in hospital consultants, general practitioners and senior health service managers. BMJ 1994;309:1261-3.

37. Chambers R, Campbell I. Anxiety and depression in general practitioners: associations with type of practice, fundholding, gender and other personal characteristics. Fam Pract 1996;13:170-3.

38. Andrews B, Hejdenberg J, Wilding J. Student anxiety and depression: comparison of questionnaire and interview assessments. J Affect Disord 2006;95:29-34.

39. Altman DG, Machin D, Bryant TN, et al. Proportions and their differences. In: Altman DG, Machin D, Bryant TN, et al., eds.
Statistics with confidence. 2nd edn. London: BMJ Books, 2000:45-56

40. R Development Core Team. R: A language and environment for statistical computing. Vienna, Austria: R Foundation for Statistical Computing, 2011. ISBN 3-900051-07-0, http://www.R-project.org/.

41. Skinner R, Conlon L, McDonald C. Cannabis use and non-clinical dimensions of psychosis in university students presenting to primary care. Acta Psychiatr Scand 2011;123:21-7.

42. Heffernan T, Clark R, Bartholomew J, et al. Does binge drinking in teenagers affect their everyday prospective memory? Drug Alcohol Depend 2010;109:73-8.

43. Matsudaira T, Kitamura T. Personality traits as risk factors of depression and anxiety among Japanese students. J Clin Psychol 2006;62:97-109.

44. Augestad LB, Slettemoen RP, Flanders WD. Physical activity and depressive symptoms among Norwegian adults aged 20-50. Public Health Nurs 2008;25:536-45.

45. Collins IP, Paykel ES. Suicide amongst Cambridge University students 1970-1996. Soc Psychiatr Epidemiol 2000;35:128-32.

46. Newbury-Birch D, Lowry RJ, Kamali F. The changing patterns of drinking. Illicit drug use, stress, anxiety and depression in dental students in a UK dental school: a longitudinal study. Br Dent $J$ 2002;192:646-9.

47. Caci H, Baylé FJ, Mattei V, et al. How does the hospital anxiety and depression scale measure anxiety and depression in health subjects? Psychiatry Res 2003;118:89-99.

48. Zoccolillo M, Murphy GE, Wetzel RD. Depression among medical students. J Affect Disord 1986;11:91-6.

49. Zivin K, Eisenberg D, Gollust SE, et al. Persistence of mental health problems and needs in a college student population. J Affect Disord 2009;117:180-5.

50. Levine RE, Breitkopf CR, Sierles FS, et al. Complications associated with surveying medical student depression. Acad Psychiatry 2003;27:12-18.

51. Enns MW, Cox BJ, Sareen J, et al. Adaptive and maladaptive perfectionism in medical students: a longitudinal investigation. Med Educ 2001;35:1034-42.

52. O'Connor LE, Berry JW, Weiss J, et al. Guilt, fear, submission and empathy in depression. J Affect Disord 2002;71:19-27. 